\title{
Socialismo, liberalismo e educação para a democracia Honneth e Dewey em discussão ${ }^{1}$
}

Socialism, Liberalism and education for democracy Honneth and Dewey in discussion

\section{Socialismo, liberalismo y educación para la democracia Honneth y Dewey en discusión}

(1) Franciele Petry ${ }^{2}$

\begin{abstract}
Resumo: O presente trabalho tem como objetivo discutir o livro de Axel Honneth, A ideia de socialismo, publicado em 2015, à luz de considerações feitas a partir dos trabalhos de John Dewey, Liberalism and social action (1935) e Democracia e educação (1916). Busca-se examinar a aproximação entre a proposta de socialismo de Honneth e a defesa de um novo liberalismo feita por Dewey. O trabalho sugere que a proposta de Honneth apresenta dificuldades decorrentes de uma apropriação insuficiente das ideias de Dewey, principalmente no que diz respeito ao papel da educação na formação da vontade democrática necessária à cooperação social.
\end{abstract}

Palavras-chave: Socialismo; Liberalismo; Democracia; Honneth; Dewey.

Abstract: This paper aims to discuss Axel Honneth's book, The idea of socialism, published in 2015, considering John Dewey's Liberalism and social action (1935) and Democracy and education (1916). It will be examined a possible approximation between Honneth's socialism and Dewey's defense of a renascent liberalism. It will be suggested that Honneth's proposal is problematic due to an insufficient appropriation of Dewey's ideas, particularly those related to the role of education within the democratic will formation, upon which social cooperation rests.

Keywords: Socialism; Liberalism; Democracy; Honneth; Dewey.

\footnotetext{
${ }^{1}$ Agradeço ao Daad pela concessão de bolsa no contexto do "Re-invitation programme for former scholarship holders" para estadia de pesquisa na J. W. Goethe Universität durante os meses de junho e julho de 2018, o que me permitiu reformular algumas ideias presentes nesta versão final do trabalho.

${ }^{2}$ Departamento de Filosofia, Universidade Federal de Santa Catarina (Ufsc, Florianópolis, SC, Brasil). 
Resumen: El presente trabajo tiene como objetivo discutir el libro de Axel Honneth, La idea de socialismo, publicado en 2015, a la luz de las consideraciones hechas a partir de los trabajos de John Dewey, Liberalism and social action (1935) y Democracy and education (1916). Se busca examinar el acercamiento entre la propuesta de socialismo de Honneth y la defensa de un nuevo liberalismo hecho por Dewey. El trabajo sugiere que la propuesta de Honneth presenta dificultades derivadas de una apropiación insuficiente de las ideas de Dewey, principalmente en lo que se refiere al papel de la educación en la formación de la voluntad democrática necesaria para la cooperación social.

Palabras clave: Socialismo; liberalismo; democracia; Honneth; Dewey.

\section{Introdução}

Em $A$ ideia de socialismo: tentativa de atualização, ${ }^{1}$ dois aspectos da reflexão apresentada por Honneth conduzem, a meu ver, a uma tensão em relação às pretensões erguidas pelo autor. $\mathrm{O}$ problema aparece quando a obra é lida paralelamente a alguns textos de Dewey, filósofo que inspira o trabalho de Honneth em diferentes momentos. ${ }^{2}$ Nesta seção, pretendo levantar algumas questões que considero problemáticas nessa última obra de Honneth para abordá-las de forma mais detalhada nas seções seguintes: primeiro, apresentando a crítica ao liberalismo de Dewey e, em seguida, a concepção de socialismo defendida por Honneth, apontando para a proximidade existente entre elas. Na última seção, gostaria de mostrar que apesar da apropriação feita por Honneth de muitos aspectos da teoria de Dewey, certas omissões fragilizaram sua proposta.

Algo que aparece já no prefácio do livro é a declaração de Honneth de que ele pretende mostrar que "o socialismo ainda contém uma faísca viva se conseguirmos extrair seu núcleo central do contexto intelectual da primeira fase do industrialismo e posicioná-lo em um novo marco sócio-teórico" (Honneth, 2017, p. viii). Por outro lado, essa que poderia ser uma reabilitação da utopia socialista encontra um limite colocado pelo próprio autor ao afirmar que suas considerações possuem um caráter metapolítico e que não serão esboçadas conexões com as constelações políticas atuais e com possibilidades para a ação (cf. Honneth, 2017, p. 5).

\footnotetext{
${ }^{1}$ Para uma contextualização crítica da obra em relação aos trabalhos anteriores de Honneth, ver Pinzani (2016) e Souza (2017).

2 Já em 1998, Honneth havia escrito o artigo Democracy as reflexive cooperation: John Dewey and the theory of democracy today, no qual faz um elogio à teoria dele ao afirmar que no debate entre republicanismo e procedimentalistas, "o modelo de democracia tardio de Dewey representa não somente uma alternativa, mas é superior às abordagens predominantes hoje" (Honneth, 1998, p. 765).
} 
As afirmações de Honneth geram, aqui, um primeiro desconforto, uma vez que se frustra, já no início, a expectativa de se encontrar na obra uma discussão que aponte para um socialismo ou movimento com potencial emancipatório efetivamente possível como programa, pensado para além da dimensão metapolítica e que leve em consideração aspectos da realidade política atual, assim como as restrições tão facilmente observáveis que ela impõe à mudança social pretendida. Dewey, nesse sentido, parece ter sido mais crítico em relação à sociedade de seu tempo quando, em uma defesa convincente sobre um novo liberalismo possível, afirmou:

Não é parte da minha tarefa delinear em detalhe um programa para o liberalismo renascente. Mas a questão "o que deve ser feito" não pode ser ignorada. Ideias devem ser organizadas e isso implica a organização de indivíduos que sustentam tais ideias, cuja crença esteja pronta para ser traduzida em ação. A tradução em ação significa que o credo geral do liberalismo seja formulado como um programa concreto de ação. É na organização para a ação que os liberais são fracos e sem ela há perigo de que os ideais democráticos sejam perdidos (Dewey, 1935, p. 91).

Dewey parece ter ido além de Honneth ao reconhecer que ainda que seja difícil traduzir em um plano concreto para a ação as ideias defendidas no plano teórico, o impulso inquietante sobre como se deve agir necessita encontrar alguma ressonância no pensamento, enfrentando as dificuldades concretas impostas pela estrutura social. A proposta de Honneth se satisfaz com a reflexão no plano metapolítico, algo que podemos compreender, por exemplo, quando lembramos o assunto um tanto espinhoso para a Teoria Crítica sobre a necessidade de uma práxis política. Nesse sentido, a fragilidade da crítica de Honneth em relação a Dewey poderia ser relativizada. Ao mesmo tempo, porém, o anseio por uma transformação social sempre tão presente na motivação dos teóricos críticos exige da teoria um movimento mais profundo ao enfrentar os problemas da sociedade presente. É em relação a essa reticência da obra de Honneth que pretendo enfatizar o modo pelo qual Dewey oferece uma crítica mais contundente.

Antes, gostaria de abordar outro ponto que considero mais problemático no livro de Honneth. Ele se refere ao modo como a ideia de socialismo será proposta, ou seja, um socialismo revitalizado a partir de vários elementos advindos da teoria de Dewey. Essa operação efetuada por Honneth, tal como pretendo mostrar, resultará em um socialismo que pode ser compreendido como uma versão do liberalismo defendido por Dewey em seu texto Liberalism and social action de 1935. É interessante notar que o próprio método utilizado 
por Honneth para reconstruir o socialismo é inspirado no modo como Dewey faz sua crítica ao liberalismo no intuito de salvaguardar um potencial ainda não realizado em função dos déficits contidos nas propostas anteriores. Quando comparada à crítica de Dewey ao liberalismo, a proposta de Honneth se revelaria problemática, uma vez que as dificuldades apontadas por aquele parecem ser desafios ainda não superados na reformulação do socialismo.

\section{Dewey e a aposta em um liberalismo renascido}

Em seu texto Liberalism and social action, Dewey faz uma crítica interna ao liberalismo, mostrando como as mudanças ocorridas desde Locke até o século 19 impediram-no de concretizar fins que estariam em conformidade com seus objetivos iniciais e que não se realizaram devido a determinados pontos cegos da posição ocupada por seus defensores. ${ }^{3}$ Para ele, a defesa de Locke da propriedade a partir da ideia de um direito natural e contra o inimigo encarnado pelos governantes em função da possibilidade de confiscá-la dá lugar, na teoria de Smith, a um direito de propriedade usado para justificar não mais a posse, mas a liberdade de seu uso e o investimento de capital. Apesar das diferenças, mostra Dewey, a preocupação com a liberdade individual se manteve, mas com Smith ela ganha novos contornos cujo efeito foi o de subordinar o âmbito político ao econômico (cf. Dewey, 1935, p. 9). Centrada na produção de riqueza e não mais na posse, a economia encontra na teoria uma possibilidade de justificação das liberdades individuais na medida em que a oposição a elas significaria uma conspiração contra as causas que levam ao progresso social. De modo análogo aos fisiocratas, Smith partiria de leis naturais, não em relação à produção, mas no que se refere à natureza humana. A simpatia, contudo, não pode se tornar uma qualidade à qual o governante apela. Em vez dela, é o exercício do autointeresse natural do indivíduo que deve ser protegido, ideia que seria melhor desenvolvida por Bentham e Mill.

Para Dewey, o liberalismo econômico, ao defender a livre atividade econômica, assumiu que a interferência do estado constituía uma ameaça à liberdade natural, surgindo daí a formulação do laissez-faire. Bentham partiria dessa ideia, mas propondo uma reformulação da common law e de procedimentos judiciais por meio de atos legislativos, pois eles poderiam restringir a liberdade, o que seria uma fonte de dor e uma limitação das possibilidades de se buscar o prazer. Essa teoria psicológica serviu para

\footnotetext{
${ }^{3}$ A reconstrução histórica feita aqui procura seguir a linha de argumentação desenvolvida no primeiro capítulo da obra Liberalism and social action.
} 
explicar o desejo pelo ganho, muito apropriado à indústria e à troca, e foi a base para o funcionamento do âmbito político e legal. Assim, os interesses emergentes puderam se amparar nas novas ideias liberais (cf. Dewey, 1935, p. 12).

Dewey procura mostrar, assim, como o liberalismo é compatível com reformas sociais. Por um lado, a formulação de Bentham atacava a desigualdade de status garantida pela lei, apontando para uma situação que poderia ser melhor caso as instituições sociais fossem transformadas. Ainda que ele indicasse apenas mudanças negativas como abusos, corrupção e desigualdade, por exemplo, nada impediria, segundo Dewey, que por sua teoria se defendesse a criação e mudança positiva de instituições, estendendo o método experimental da ciência para a moral e não meramente no plano teórico, mas também prático. Ao elogiar a atuação de Bentham como crítico das leis de seu tempo, Dewey pretende destacar que o liberalismo não está internamente vinculado à impossibilidade de mudanças radicais na sociedade. Elas não viriam com os liberais assumindo o poder, antes, deveriam ocorrer numa esfera diferente da governamental, mas com atenção pública e subsidiada por uma inteligência política. Dewey reconhece ainda que a psicologia defendida por Bentham era rudimentar, mas vê positivamente a avaliação dos costumes e instituições segundo as consequências que geram no plano individual, as quais poderiam levar os cidadãos à desobediência e à exigência por reformas. Segundo Dewey, ao criticar o direito natural, Bentham abriu espaço para uma intervenção estatal justificada pela promoção de bem-estar geral, distanciando-se, assim, dos economistas liberais e aproximando-se de um liberalismo coletivista. $^{4}$

O liberalismo, a partir dessas mudanças, incorporou também uma crítica às suas primeiras formulações. Com Hill Green, aparece a defesa do associacionismo, ainda que tenha permanecido a defesa dos ideais liberais; com os idealistas, o liberalismo passa a contar com uma interpretação da liberdade como algo a ser conquistado pelo indivíduo (e não como algo já possuído de antemão), contando com o auxílio do estado. Tais ideias provocaram, segundo Dewey, uma transformação no liberalismo, mas a crítica interna também teve como consequência uma certa crise. Para o autor, os liberais das primeiras

\footnotetext{
${ }^{4}$ Essa transformação do liberalismo, segundo Dewey, ocorre por influência do humanismo, do romantismo e do pietismo, e pode ser observada teoria de Mill. Desde a defesa de que "a autoproteção constitui a única finalidade pela qual se garante à humanidade, individual ou coletivamente, interferir na liberdade de ação de qualquer um", Mill teria travado uma luta para conciliar sua teoria com o valor da poesia, da vida interior e com o fortalecimento das instituições, tal como defendiam os românticos (cf. Dewey, 1935, p. 23).
} 
décadas do século 19 foram potentes em suas críticas e análises ao liberar forças que havia sido postas em cheque. ${ }^{5}$ Entretanto, diz o autor, "análise não é construção e a liberação das forças não dá, por si só, direção a elas" (Dewey, 1935, p. 28).

A crise do liberalismo estaria relacionada, segundo Dewey, à dificuldade em se estabelecer uma conexão entre liberdade individual e organização social, em se incluir atividades econômicas que pudessem ser meio para o desenvolvimento das capacidades dos indivíduos. Por isso é que ideais fundamentais como a liberdade, o desenvolvimento das capacidades inerentes aos indivíduos que são possíveis pelo exercício da liberdade, e o papel de uma inteligência livre na investigação, discussão e expressão, foram, de certa forma, pervertidas e não realizadas dentro da organização social.

Um dos equívocos apontados por Dewey nas formulações do liberalismo é a falta de sentido e de interesse histórico, manifestos em suas interpretações de liberdade, individualidade e inteligência. Assim, foram cegos para a forma como as condições sociais produzem a liberdade, para o modo como as forças econômicas moldam as relações entre os indivíduos, o que implicaria no controle delas em função da massa de indivíduos. Para Dewey, foi porque os liberais falharam em distinguir uma liberdade meramente formal ou legal de uma liberdade efetiva de pensamento e ação que os ideais contidos nas teorias não puderam ser realizados (cf. Dewey, 1935, p. 32). Essa compreensão histórica insuficiente da ideia de liberdade os levou a fortalecer uma forma de organização social que iria contra os próprios princípios liberais.

Outro grande equívoco foi o de terem se preocupado apenas com o controle do autointeresse dos governantes, sem prestar atenção no interesse das forças econômicas que afetavam a vida dos indivíduos e impediam uma conciliação de liberdade com igualdade. A desigualdade foi se tornando cada vez mais aparente com o liberalismo do laissez faire e justificada, por um lado, a partir de teorias psicológicas e morais defensoras do livre jogo das diferenças individuais que criaria, naturalmente, as desigualdades, ou, por outro lado, por uma glorificação de qualidades individuais, tais como as virtudes de inciativa, independência, escolha, responsabilidade. Na base do liberalismo encontrava-se uma concepção de individualidade como algo pronto, cuja realização plena só dependia de se alterar determinados arranjos externos, os quais, contudo, não implicavam em uma modificação interna dos indivíduos. É como se

\footnotetext{
${ }^{5}$ A partir daqui, a reconstrução da argumentação de Dewey sobre o desenvolvimento do liberalismo se baseia, principalmente, no segundo capítulo do livro Liberalism and social action.
} 
defendessem um estado de natureza do indivíduo anterior à associação com outros indivíduos. Além disso, Dewey critica a falha dos liberais em compreender a inteligência, tratada como posse simples individual. Apesar da defesa da liberdade de pensamento, consciência, expressão e comunicação, tais qualidades não foram concebidas em sua contribuição como direção para a organização social (cf. Dewey, 1935, p. 42).

A partir dessas críticas, Dewey defenderá uma forma de liberalismo que torne possível a liberdade efetiva e ofereça aos indivíduos oportunidades para seu desenvolvimento. ${ }^{6}$ Esse liberalismo renascido atuaria na formação de novos padrões morais e intelectuais, além de uma mudança nas instituições. Mas, para isso, Dewey atribui à educação um papel central, não como acúmulo de conhecimentos, mas como formação de hábitos e disposições internas. Sua proposta é usar a ação inteligente como direção social. O método científico, assim como as tecnologias, é a força que contém possibilidades de revolucionar a sociedade. Contudo, o descompasso entre seu avanço e, por outro lado, uma mentalidade estática, pré-científica e pré-tecnológica, impede que a sociedade se desenvolva de forma cooperativa. O liberalismo que Dewey aponta como necessidade é radical: impõe transformações profundas na sociedade. Se não for assim, diz Dewey, ele se tornará irrelevante (cf. Dewey, 1935, p. 62). Radicalismo, porém, não significa o uso da força, mas de uma inteligência que por meio da democracia eleva os conflitos existentes na sociedade a um patamar de discussão. Dewey conclui seu texto se referindo à socialização das forças de produção. Para ele, "a causa do liberalismo será perdida por um período considerável se ele não estiver preparado para ir adiante e socializar as forças de produção disponíveis hoje de modo que a liberdade dos indivíduos seja amparada pela estrutura da organização econômica" (Dewey, 1935, p. 88). Uma economia socializada é meio, portanto, para o desenvolvimento livre do indivíduo, o qual é o fim que dirige a ação social. A partir da reconstrução da proposta de um liberalismo renascido de Dewey podemos observar os pontos de contato com a ideia de socialismo de Honneth.

\section{A ideia de socialismo de Honneth e sua aproximação com o liberalismo de Dewey}

Em sua reconstrução histórica do socialismo, uma das críticas feitas por Honneth é a de que os primeiros socialistas assumiram que a noção de liberdade individual não era conciliável com o princípio da fraternidade, o que os levou a buscar sua expansão. Assim, por uma crítica imanente

\footnotetext{
${ }^{6}$ Tal defesa é apresentada no terceiro capítulo da obra em questão.
} 
ao capitalismo, defenderam a submissão da esfera econômica à ampliação da liberdade individual em uma forma mais intersubjetiva, como livre cooperação. Esta, porém, não seria apenas condição para a liberdade, mas seu verdadeiro exercício. A noção de uma comunidade pressuporia a ideia de que cada indivíduo é simpático ao outro e apoia a realização das necessidades justificadas dos outros. Essa comunidade solidária realizaria a conciliação da liberdade com a fraternidade. O problema de tal concepção, segundo Honneth, é que os primeiros socialistas restringiram a liberdade social ao âmbito econômico, ignorando a esfera de deliberação política.

Também a criação de laços de solidariedade seria uma dificuldade relacionada a essa difícil conciliação no socialismo entre liberdade e fraternidade. Ainda que as respostas dos socialistas tenham indicado que o caminho estaria na superação da economia de mercado capitalista, a qual cria a ideia de liberdade centrada exclusivamente nos interesses privados dos indivíduos, Honneth critica essa visão. Para ele, os socialistas foram incapazes de compreender o valor dos direitos individuais, estando a liberdade social acima deles, restringindo o potencial emancipatório daqueles na esfera política, ou seja, sem considerá-los como possibilidade de formação geral da vontade necessária à própria democracia.

Outra ideia comum aos socialistas criticada por Honneth é a de que a transformação econômica pelas mãos de uma classe de oposição levaria a uma economia cooperativa. Para Honneth, essa foi uma pressuposição arbitrária e autorreferencial, não uma constatação de um movimento de resistência. Recorrendo a Horkheimer, Honneth chama a atenção para o caráter fictício de uma suposta classe trabalhadora revolucionária. Pensada no contexto da sociedade pós-industrial, a ideia dos socialistas se revelaria ainda mais inócua, sem correspondência com um sujeito revolucionário do qual a teoria seria expressão intelectual.

O terceiro ponto debatido por Honneth é a visão do socialismo como desenvolvimento histórico necessário, o qual, independentemente da versão de filosofia da história que se adote, estaria em condições de resolver as contradições do capitalismo, promovendo o surgimento de uma sociedade cooperativa. Sob a influência de Dewey, Honneth condena os socialistas por excluírem a experimentação, convencidos de que já conheciam a melhor forma de organização social da liberdade, a economia planificada.

É a partir dessas críticas que Honneth apresentará sua versão atualizada de socialismo, corrigida de seus problemas. A ideia a ser defendida irá buscar nas forças existentes socialmente a possibilidade de renovação do socialismo, mais precisamente, deverá encontrar um lugar para a liberdade 
social. Diferentemente da tradição socialista que localizava sua possibilidade na esfera econômica, Honneth a estenderá para a esfera política pública em que indivíduos podem participar por meio da livre comunicação. Assim, será possível conciliar tal forma de socialismo com a democracia.

Para fugir da limitação dos primeiros socialistas em pensar a transformação social por meio de uma economia planificada e centralizada, a única que, segundo Honneth, Marx possibilitou a eles pensar, seria necessário revisar a relação entre economia de mercado e capitalismo a fim de permitir formas alternativas de mercado voltadas para a cooperação social. Na verdade, Honneth chega a afirmar que o socialismo renovado deverá se utilizar da experimentação para descobrir de que modo a realização da liberdade social seria possível, seja pelo mercado, pela sociedade civil ou por um estado constitucional democrático (cf. Honneth, 2017, p. 58).

Nesse ponto, Honneth se torna mais enfático em suas referências a Dewey. A primeira delas faz uso da experimentação que, como mencionado, permite reconhecer potenciais existentes na sociedade para transformá-la, abrindo mão da crença em uma direção necessária do progresso humano. A experimentação assumida por Dewey é, segundo Honneth, surpreendentemente próxima das ideias originais do socialismo. E é nessa afinidade de Dewey com o socialismo que Honneth encontrará possibilidades conceituais para redefini-lo na sociedade contemporânea.

De Dewey, então, virá a ideia de que uma sociedade livre de barreiras à comunicação e de restrições à interação é capaz de buscar seu aprimoramento social. A experimentação se apoiará nessa base relativa à participação efetiva dos membros nas discussões concernentes aos problemas da sociedade. Os grupos sociais excluídos lutarão para se integrar, expandindo as barreiras da comunicação e interação. O socialismo passa a ser, na visão de Honneth, a efetivação da participação social em processos democráticos, ampliando a liberdade a ponto de ela ganhar a dimensão social expressa pela cooperação entre os membros da sociedade. Assim, a liberdade social se torna compatível com a fraternidade, avançando naquela que era uma dificuldade dos primeiros socialistas.

O problema da proposta de Honneth, porém, não está nessa adesão aos pressupostos vindos da teoria de Dewey, mas na relação do socialismo com o capitalismo. Honneth, justificando-se a partir do método da experimentação, afirma que não é mais claro como a liberdade social pode ser realizada na esfera econômica. Por isso a necessidade de se tentar outros modelos de economia de mercado que possam dar vazão aos potenciais emancipatórios que, de outro lado, a esfera social ainda apresenta. O objetivo seria chegar a um modelo em 
que se pudesse "liberar os produtores de restrições e dependência, permitindo a eles verem a si próprios como contribuintes livres à tarefa de satisfazer igualmente as necessidades de todos os membros da sociedade, tarefa que só pode ser cumprida na reciprocidade" (Honneth, 2017, p. 69). Honneth não chega a afirmar que isso é possível no capitalismo, deixando aberta a questão de se a cooperação econômica poderia ser alcançada pela expropriação da propriedade privada ou se é incompatível com as formas existentes de propriedade. Como se pode perceber, esse novo socialismo não representa o interesse de um determinado grupo social, mas os interesses articulados dos indivíduos que, cooperativamente, levam a uma sociedade gradualmente mais democrática e voltada para uma direção de crescimento comum, tendo como base a investigação de alternativas a partir das possibilidades já existentes na realidade, assim como a reforma de suas instituições (cf. Honneth, 2017, p. 74).

Desse modo, o socialismo de Honneth superaria a difícil relação dos primeiros socialistas com a democracia política, e também com o liberalismo. Segundo Honneth, a distinção liberal entre sociedade e estado, esfera privada e pública, economia e estado, não foi reconhecida pelos primeiros socialistas, pois eles se mostraram incapazes de compreender a diferenciação funcional da sociedade devido à falha em distinguir o âmbito empírico do normativo (cf. Honneth, 2017, p. 80). Tampouco compreenderam a importância dos direitos e de seu potencial emancipatório no processo de formação da vontade política, já que não operaram efetivamente a partir da ideia de uma liberdade social realizada por meio da comunicação livre entre participantes, nem mesmo reconheceram a vontade popular em processos legislativos. Deixaram, portanto, de observar o modo pelo qual outras esferas sociais, independentes das relações de produção, se mostrariam adequadas à realidade da liberdade. Somente teriam sido solidários à causa da emancipação feminina dos homens por sua integração em relações associativas de produção, mas também aqui o olhar dos socialistas se deteve somente à esfera econômica.

Para Honneth, a democracia pensada como uma forma de vida que reflete a livre cooperação fornece aos seus membros a oportunidade de participação equitativa nos processos de mediação entre indivíduo e sociedade, de modo a haver uma relação orgânica e harmoniosa de uma liberdade que se realiza em termos sociais, preservando a independência entre as diferentes esferas - relações pessoais, economia e formação da vontade democrática. Cooperativamente e por meio de um processo reflexivo de deliberação pública, os indivíduos se envolveriam na resolução dos problemas, baseados no método da experimentação. 
Essas, que são ideias advindas da teoria de Dewey, são tomadas aqui em oposição ao liberalismo que, tal como Honneth o apresenta, centra-se na realização privada da liberdade. Dewey se torna, nessa acepção, próximo do socialismo, uma vez que defende a liberdade compreendida em termos sociais. É nesse sentido que eu gostaria de chamar a atenção para o resultado da operação de renovação do socialismo feita por Honneth que, ao final, o leva a uma proposta semelhante à de Dewey.

Contudo, certas questões abordadas por Dewey em sua defesa do liberalismo e de seus pressupostos parecem ser insuficientemente tratadas por Honneth, como, por exemplo, a crítica ao individualismo e ao capitalismo, os quais representam obstáculos à vida cooperativa e, portanto, à realização da liberdade social. ${ }^{7}$ Além disso, uma das questões centrais para a possibilidade de realização do liberalismo renascido de Dewey é uma concepção de educação como base para a formação do indivíduo que pensa e age em termos de associação, algo ignorado nessa obra de Honneth. Na próxima seção, considerando a aproximação teórica das duas propostas, pretendo discutir os aspectos da teoria de Dewey que não foram retomados por Honneth em sua reconstrução do socialismo, apontando para as dificuldades resultantes.

\section{Educação como condição para a vida cooperativa e democrática}

$\mathrm{Na}$ reconstrução histórica que Dewey fez sobre o desenvolvimento do liberalismo, o autor aponta para a ênfase dada ao individualismo e à proteção das liberdades, algo que motivou inicialmente a organização democrática, mas, ao final, solapou a possibilidade de que os indivíduos se reconhecessem em uma comunidade. ${ }^{8}$ Honneth, por sua vez, também destaca o modo pelo qual a liberdade social, compreendida de modo insuficiente pelos primeiros socialistas,

\footnotetext{
${ }^{7}$ É certo que em sua obra $O$ direito da liberdade, Honneth, com sua reconstrução normativa, discute como a liberdade social se realiza nas três esferas da sociedade (relações íntimas, mercado e Estado democrático), enfrentando também as dificuldades que elas colocam àquela realização. Ao mesmo tempo, o próprio autor reconhece que $A$ ideia de socialismo surge em parte como tentativa de responder às críticas recebidas em razão da publicação de $O$ direito da liberdade, uma vez que o ponto de partida normativo teria sido insuficiente para a perspectiva crítica de transformação da ordem social existente (cf. Honneth, 2017, p. viii). Neste trabalho, optou-se por uma abordagem que enfatiza o aspecto educacional, o qual se mostra um dos pilares da proposta do liberalismo de Dewey e que também seria fundamental para a ideia de socialismo apresentada por Honneth. Outras possibilidades de crítica que levem em consideração a aproximação das propostas de ambos os autores serão desenvolvidas em trabalhos futuros.

${ }^{8}$ Esse problema havia sido indicado também em The public and its problems, de 1927, em que Dewey mostra como o "público" não conseguiu se organizar de forma democrática, prevalecendo, ainda, relações de poder em que predominam interesses privados (cf. Dewey, 2016, p. 143).
} 
deveria se realizar para além da esfera econômica a fim de possibilitar a formação da vontade democrática. Embora Honneth chame a atenção, constantemente, para a necessidade de um olhar voltado à experimentação histórica, não coloca em questão em $A$ ideia de socialismo como a sociedade contemporânea poderia combater o individualismo ainda presente e que impede a cooperação social entre os indivíduos.

A esse respeito, Dewey parece ter sido mais enfático ao mostrar a dificuldade que tal visão colocava ao desenvolvimento de uma forma de vida associada, mas encontrou uma saída para salvaguardar a possibilidade de uma sociedade organizada democraticamente. Ela estava na formação de hábitos e disposições internas que levariam a um pensamento inteligente e voltado para a cooperação social. Tal formação ocorreria por meio da educação, a qual, se bem dirigida, proporcionaria desde a infância oportunidades de experiências positivas que promoveriam o desenvolvimento individual em conexão com a vida social.

Em Democracia e educação, de 1916, Dewey já havia se dedicado ao tema da educação como base para a democracia: uma formação adequada dos indivíduos promoveria a criação de hábitos indispensáveis para a participação em atividades comuns, as quais possibilitam, justamente, o desenvolvimento de uma liberdade em termos sociais. Um indivíduo formado para a cooperação social deve, necessariamente, pensar sua atividade em conexão com as demais. É nesse contexto que Dewey concebe a educação como possibilidade de crescimento, não apenas do indivíduo, mas da sociedade. A experiência que a educação deve promover é compreendida como continuidade e renovação da vida social (cf. Dewey, 1979, p. 10) e, por isso, é fundamental que ela seja dotada de um caráter intelectual, o qual lhe confere um método reflexivo para que o crescimento esteja direcionado à atividade social. $\mathrm{O}$ indivíduo, ao agir, é capaz de observar sua situação presente a partir do conhecimento gerado por experiências passadas, suas ou aquelas reunidas na forma do saber acumulado, e tomar decisões que levem em consideração as consequências de sua ação. Essa forma inteligente de agir, quando orientada segundo a ideia de um crescimento social e de uma vida associada, permitiria a cooperação social. A divisão do trabalho, porém, é uma das situações sociais que limitam aquela forma de vida. Para Dewey,

a eficiência da produção exige com frequência a divisão do trabalho. Mas esta se reduzirá a uma rotina maquinal se o trabalhador não vir as relações técnicas, intelectuais e sociais encerradas naquilo que está fazendo, em relação às demais partes do trabalho, e não se 
dedicar a seu trabalho por essa compreensão. A tendência a reduzir coisas como a eficácia da atividade e a organização científica do trabalho a técnicas puramente externas é a prova do ponto de vista unilateral que possuem os que dirigem a indústria - aqueles que lhe determinam os fins (Dewey, 1979, p. 91).

Assim, considerando que a sociedade apresenta vários obstáculos à realização de uma vida associada e que o meio social é importante formador das disposições dos indivíduos, Dewey ressalta a importância da escola para restaurar, pela oportunidade de um livre intercâmbio de experiências, os desiquilíbrios provenientes das desigualdades sociais e culturais. Reserva a ela as funções de oferecer um ambiente simplificado para que as experiências sejam realizadas de forma gradativa, progredindo das mais simples às complexas; de eliminar os aspectos desvantajosos do meio social a fim de criar um ambiente purificado para a formação de hábitos que contribuam ao desenvolvimento das crianças e dos jovens e, além disso, de "contrabalançar os vários elementos do ambiente social e ter em vista dar a cada indivíduo oportunidade para fugir às limitações do grupo social em que nasceu, entrando em contacto vital com um ambiente mais amplo" (Dewey, 1979, p. 22). A escola, portanto, é meio fundamental para criar no indivíduo a forma de agir orientada para a participação na vida social, criando interesses em atividades comuns e uma compreensão sobre a significação social das ações.

Dewey avança na crítica ao localizar na sociedade dividida em classes, decorrente das condições econômicas, um empecilho à cooperação social, já que no uso instrumental de uma classe por outra, a dominada é limitada em sua possibilidade de desenvolvimento e de participação na vida social. Mais uma vez, a educação é defendida enfaticamente, não somente no sentido de ser necessário impedir que seja usada para dar continuidade a essa forma de dominação de uma classe por outro, como também para que sejam asseguradas "as facilidades escolares com tal amplitude e eficácia que, de fato, e não em nome somente, se diminuam os efeitos das desigualdades econômicas e se outorgue a todos os cidadãos a igualdade de preparo para suas futuras carreiras" (Dewey, 1979, p. 105).

Essa divisão encontra, segundo Dewey, uma correlação na forma como as concepções acerca da educação se desenvolveram historicamente. A separação entre uma educação liberal e outra profissional e industrial, que remonta à Grécia, legitima a ideia de que uma classe deve ser formada para o trabalho enquanto a outra, por dele estar liberada, pode se dedicar ao ócio, à cultura e ao emprego da inteligência, sendo esse último tipo de formação, no discurso pedagógico, considerada mais elevada (cf. Dewey, 1979, p. 276). Dewey é 
severo na crítica, pois não bastaria alterar conceitos ou promover sentimentos favoráveis em relação ao trabalho:

Importantes como são estas mudanças teóricas e emocionais, elas só se completarão quando se refletirem no desenvolvimento de uma sociedade democrática, sociedade em que todos tomem parte em serviços de utilidade prática e todos desfrutem nobres ócios. Não é a simples mudança dos conceitos, da cultura - ou da mentalidade liberal - e dos serviços sociais, que requer uma reorganização educacional - necessita-se, sim, da transformação educacional para fazer que produzam plenos e manifestos resultados as mudanças realizadas na ordem social (Dewey, 1979, p. 282).

Além disso, o dualismo entre trabalho manual e intelectual, amparado por ideias pedagógicas, faz com que a educação da classe trabalhadora seja limitada a poucos anos de estudo, à aquisição de habilidades básicas, enquanto a educação liberal se destina ao estudo das ciências naturais, da literatura e história (cf. Dewey, 1979, p. 285). Como consequência, a classe trabalhadora acaba exercendo atividades que reproduzem a dominação de classes já existente desde a sua formação. Sem a possibilidade de um livre desenvolvimento que abranja toda a sociedade, a cooperação social não se realiza. De acordo com Dewey,

mais importante é o fato de a grande maioria dos trabalhadores não conhecer as finalidades sociais de seu labor e não ter nele um interesse direto pessoal. Os resultados que eles obtêm com seus esforços não são o objetivo de suas ações e sim unicamente o objetivo de seus superiores. Eles não fazem livre e inteligentemente o seu trabalho e sim tendo em vista o salário a ganhar. Esta é a circunstância que torna iliberal o seu trabalho e esse efeito é o que torna iliberal e imoral qualquer educação destinada unicamente a dar habilidade a tais trabalhos. A atividade não é livre porque não é livremente que se participa da mesma (Dewey, 1979, p. 285).

A educação que se volta para a defesa de uma sociedade democrática deve, então, enfrentar a situação econômica, buscando eliminar as desigualdades que geram diferentes possibilidades de desenvolvimento, criando privilégios para uns e restrições para outros. Essa preocupação alcança inclusive a seleção do programa de estudos, pois, segundo Dewey, “a democracia não pode florescer quando os principais critérios para a escolha das matérias educativas são os fins utilitários estreitamente concebidos para as massas, e, quando se escolhem para a instrução mais elevada dos outros poucos, as tradições de uma classe instruída especializada" (Dewey, 1979, p. 212). A dissolução dos 
dualismos existentes na educação, reprodutores da divisão social, precisam ser superados a fim de que uma concepção que tenha em vista uma direção comum à sociedade possa predominar sobre interesses exclusivos de determinados grupos.

De forma análoga ao modo como criticou o liberalismo e suas promessas não cumpridas, Dewey reconhece na educação forças que podem ser utilizadas para uma transformação radical da sociedade. Assim, além de pensar os problemas da sociedade de seu tempo, enfrentando aspectos da realidade que poderiam colocar em questão uma teoria caracterizada de forma ideal, Dewey considerou os obstáculos reais no interior de sua concepção sobre a educação, sobre a democracia e sobre a realização do liberalismo, oferecendo alternativas possíveis para renovar a vida que se encontrava ameaçada em seu crescimento social.

Em A ideia de socialismo, como já mencionado anteriormente, Honneth considera a renovação do socialismo a partir tanto da possibilidade de pensar formas alternativas de mercado voltadas para a cooperação social, quanto por uma maior e mais livre participação dos indivíduos na esfera pública, o que ocorreria no contexto da deliberação política. Aqui, então, seria importante, assim como Dewey o fez, tratar da formação dessa vontade democrática que se dirige à cooperação, uma vez que a transformação das condições sociais existentes passaria pela compreensão dos limites que se colocam à esfera pública e dificultam, inclusive, a realização de experimentos sociais. ${ }^{9}$

Embora em $A$ ideia de socialismo Honneth não aborde o tema, tal discussão foi realizada por ele em seu artigo Educação e esfera pública democrática. Neste texto, Honneth parte da afirmação de que "qualquer noção de que uma democracia vital precisa primeiro gerar, através de processos de formação geral, os pressupostos de sua própria subsistência cultural e moral foi entrementes perdida pela filosofia política" (Honneth, 2013, 547). As razões para o desligamento entre a filosofia política e a reflexão sobre a educação se devem a uma "afinidade eletiva" entre concepções sobre os pressupostos culturais da democracia e um imperativo de neutralidade estatal. Ambas as

\footnotetext{
${ }^{9}$ Em relação a este ponto, Pinzani afirma que o sujeito da transformação social atribuído por Honneth à esfera pública "é um sujeito difícil de ser definido, que perde facilmente atenção para certas temáticas e que só sabe reagir aos problemas quando eles se manifestam de forma dramática, como reconhece o próprio Honneth. Igualmente, Honneth parece subestimar a influência decisiva que interesses econômicos específicos e uma mídia sempre menos independente e cada vez mais porta-voz de grupos restritos exercem nos processos decisórios. Se é verdade que é necessário incluir na teoria socialista as outras esferas, é inegável que essas são cada vez mais sujeitas aos imperativos da economia e que hoje mais do que nunca é importante chamar a atenção para a dimensão meramente econômica que tende a prevalecer no debate público e na vida privada dos indivíduos" (Pinzani, 2016, p. 199).
} 
posições são, para Honneth, problemáticas (Cf. Honneth, 2013, 547). Por um lado, as teorias da democracia renunciaram à crença no valor da educação organizada pelo estado para a formação da vontade. Por influência da tese de Böckenförde, a formação da vontade democrática passou a ser atribuída mais aos ambientes pré-políticos com forte orientação ética ou até mesmo religiosa do que às condições culturais e morais presentes na própria democracia. Além disso, contribuiu para a separação entre filosofia política e pedagogia uma “(...) propensão a interpretar o imperativo da neutralidade do estado de modo tão restritivo que até mesmo os princípios da formação da vontade democrática não podem mais se expressar de modo algum no ensino escolar público" (Honneth, 2013, 551). Segundo Honneth, passou a ser questionável a compreensão presente na tradição desde Kant até Durkheim e Dewey segundo a qual "(...) o ensino promovido pelo estado deve corporificar exatamente os valores que se expressaram na decisão de torná-lo obrigatório para todos os futuros cidadãos (...)" (Honneth, 2013, 551), ou seja, a ideia de que o direito dos pais de transmitir seus valores aos filhos acabava no portão da escola, entendida como responsável pela educação no sentido da formação da vontade pública, perdeu sua naturalidade normativa. ${ }^{10}$

Em Dewey e Durkheim, respeitadas as diferenças, Honneth observa a concordância com a ideia de que importa menos à educação para a formação do cidadão a transmissão de conhecimentos do que a formação de hábitos práticos que contribuam com a cooperação social. Embora possa haver tendências na sociedade que aprofundem essas concepções, Honneth cita levantamentos empíricos de pesquisa comparada em formação e estudos do Pisa para mostrar que as escolas com melhores resultados são aquelas em que os ideais democráticos foram melhor realizados, como seria o caso das escolas finlandesas. Ainda que as descrições deste sistema escolar não empreguem o vocabulário de Durkheim ou Dewey,

manifestariam, então, o feliz acaso, raro e historicamente improvável, de que o político e normativamente correto coincidiria, uma vez, com o pragmaticamente adequado: as melhores formas escolares para as realizações e capacidades cognitivas dos alunos são aquelas que, ao mesmo tempo, vêm mais acentuadamente ao encontro da regeneração de condutas democráticas (Honneth, 2013, p. 558).

\footnotetext{
${ }^{10}$ Não caberá, aqui, reconstruir detalhadamente a argumentação de Honneth em seu artigo, apenas comentar as posições principais defendidas no texto.
} 
Após mostrar que o vínculo entre teorias da democracia e educação persiste na sociedade contemporânea e que a educação pública deveria ser considerada "órgão central da autorreprodução das democracias", Honneth salienta o desafio ainda existente em definir quais conteúdos deveriam fazer parte do ensino a fim de contribuir com tal objetivo de formação. Frente a fenômenos contemporâneos como a revolução digital e o multiculturalismo, que criam novas formas de interação, inclusive em esferas públicas na rede, exigindo um tratamento das diferenças culturais, a educação democrática já teria desenvolvido respostas metodológicas que apontam para a necessidade de se considerar os alunos como membros de um aprendizado cooperativo e em que as diferenças sejam oportunidades para o crescimento mútuo, porém, permaneceria aberta a questão de quais matérias deveriam ser ensinadas nesses novos contextos.

Observa-se na posição defendida por Honneth a preocupação em fortalecer a relação entre democracia e educação, tal como ela se apresentava em Dewey. Além de retomar as ideias deste, Honneth avança na consideração de alguns problemas contemporâneos ligados à formação da vontade democrática. O texto, originalmente uma conferência realizada em 2012 e posterior à publicação da obra $O$ direito da liberdade, da mesma forma como em $A$ ideia de socialismo, não aprofunda a discussão sobre a influência que aspectos econômicos teriam sobre a formação da vontade democrática, nem sobre o modo como a atual organização social impõe demandas à educação na direção oposta à cooperação social. Nesse sentido, cabe ainda se debruçar sobre tais problemas não apenas do ponto de vista normativo, mas com o auxílio de análises sociológicas que permitam compreender os obstáculos que se colocam à realização de uma forma de vida democrática.

\section{Considerações finais}

Em face das críticas feitas por Dewey a aspectos limitadores da cooperação social, podemos observar que a proposta de atualização do socialismo feita por Honneth necessitaria lidar, entre outras questões, com as dificuldades que se apresentam à formação da vontade democrática. Apesar de se apropriar de vários elementos da teoria de Dewey, Honneth deixou de lado, em $A$ ideia de socialismo, a reflexão sobre a educação como espaço necessário para a formação de hábitos e disposições internas capazes de superar o individualismo que bloqueia o sentido e a dinâmica da cooperação social, bem como o próprio exercício da liberdade social na esfera pública.

Como defende Dewey, em uma sociedade desigual no oferecimento de oportunidades para o crescimento de seus membros, a educação é um 
modo de equilibrar e diminuir as restrições sociais e econômicas impostas a determinados grupos, promovendo uma forma de pensar que articula as ações e suas consequências no contexto mais amplo da sociedade. Entretanto, a proposta educacional não é ingênua. A reconstrução crítica do liberalismo aponta para vários problemas que o impediram de realizar seus potenciais liberadores de forma estendida, legitimando, por outro lado, a opressão que se manteve em relação a determinados grupos, excluídos das oportunidades de se desenvolverem livremente de acordo com seus interesses. Assim, Dewey avançou também na crítica à divisão de classes e ao trabalho, pois o modo pelo qual foram organizados, somando-se às restrições sofridas por determinados grupos sociais, tornou impossível a efetiva participação na vida social.

Honneth, por sua vez, defende sua proposta sem problematizar as dificuldades atuais de se realizar a liberdade social na esfera política, que ele assume ser independente da econômica. Essa fragilidade parece colocar Honneth na mesma posição criticada por ele nos socialistas. Se estes possuíam um déficit na análise empírica, Honneth incorre no mesmo erro ao ignorar a discussão sobre a forma como a presente situação social impede a realização da liberdade social e sobre como os antagonismos sociais próprios do capitalismo atuam em forte oposição à cooperação social e à formação da vontade democrática. É nesse contexto que as reflexões de Dewey sobre a necessidade de realizar aquilo que o liberalismo deixou para trás e sobre o modo como a educação oferece condições para tal objetivo ainda se mostram relevantes para avançar a compreensão de como o socialismo de Honneth, condizente com o liberalismo social, poderia ser atualizado em nossa sociedade.

\section{Referências}

DEWEY, John. Liberalism and social action. New York: G. P. Putnam's Sons, 1935.

DEWEY, John. Democracia e educação: introdução à filosofia da educação. São Paulo: Companhia Editora Nacional, 1979.

DEWEY, John. The public and its problems: an essay in political theory. Ohio: Swallow Press, 2016.

HONNETH, Axel. Democracy as reflexive cooperation: John Dewey and the Theory of Democracy Today. Political Theory, v. 26, n. 6, p. 763-783, $1998<10.1177 / 00905$ 91798026006001>.

HONNETH, Axel. Educação e esfera pública democrática: um capítulo negligenciado da filosofia política, v. 13, n. 3, p. 544-562, $2013<10.15448 / 1984-7289.2013$. $3.16529>$.

HONNETH, Axel. O direito da liberdade. São Paulo: Martins Fontes, 2015. 
HONNETH, Axel. The idea of socialism: towars a renewal. Cambridge: Polity Press, 2017.

SOUZA, Luiz. G. C. Axel Honneth e a reformulação da ideia do socialismo: dos proletários aos cidadãos. Ideação, v. 1, p. 121-143, 2017.

PINZANI, Alessandro. Resenha de Die Idee von Sozialismus de A. Honneth. Ethic@, Florianópolis, v. 15, n. 1, p. 191-200, 2016.

Recebido em: 28 fev. 2018

Aprovado em: 27 set. 2018

Autora correspondente:

Franciele Petry

Departamento de Filosofia - CFH

Universidade Federal de Santa Catarina

88040-900 Florianópolis, SC, Brazil

FRANCIELE PETRY <ffpetry@yahoo.com.br>

Doutora em Educação e em Filosofia pela Universidade Federal de Santa Catarina (Ufsc, Flprianópolis, SC, Brasil), professora do Departamento de Filosofia da mesma universidade.

ORCID: https://orcid.org/0000-0002-3646-9228 